\title{
Variations of Renal Artery - A Multi-Detector Computed Tomography Study
}

\author{
Anurag ${ }^{1}$, Vishnu Gupta ${ }^{2}$ \\ ${ }^{1}$ Assistant Prof. Department of Anatomy, Muzzafarnagar Medical College, Muzzafarnagar, UP, ${ }^{2}$ Professor \& Head, Department of Anatomy, Muzzafarnagar \\ Medical College, Muzzafarnagar, UP..
}

\section{Abstract}

Introduction: The anatomical knowledge of renal artery variations is gaining importance due to increased incidence of kidney transplantation and related surgical procedures. Normally a single renal artery supplies each kidney. Accessory renal arteries are the commonly seen renovascular variations. So a thorough knowledge of renal arteries is helpful for the smooth conduct and interpretation of interventional radiological procedures and to avoid unexpected complications during surgery. Subjects and Methods: In our study we decided to find out the incidence of accessory renal arteryand also there length and diameter. Results: We studied 60 patients who came for abdominal CT angiography. In CT angiography out of 60 cases 21 cases (35\%) had renal artery variation, out of 21 cases 3 cases had bilateral renal artery variations and 2 cases had double accessory renal artery. Conclusion: Knowledge on renal artery variations are necessary during renal transplantation, urological procedures and for radiological interventions.

Keywords: Accessory renal artery, Renovascular pattern,CT angiography.

Corresponding Author: Dr. Anurag, Assistant Prof. Department of Anatomy, Muzzafarnagar Medical College, Muzzafarnagar, UP.

Received: December 2019

Accepted: December 2019

\section{Introduction}

Anatomy of renal arteries, their variations and the presence of accessory renal arteries has become a topic of interest for both anatomists and clinicians in the recent past, specially with the advent of renal transplant, urological, vascular and oncological surgeries. A thorough knowledge of renal arteries is helpful for the smooth conduct and interpretation of interventional radiological procedures and to avoid unexpected complications during surgery. The paired renal arteries take about $20 \%$ of the cardiac output and branched laterally from the aorta, below the origin of the superior mesenteric artery. Right renal artery is longer than left renal artery. Each artery divides near the hilum in to an anterior and a posterior division and these divide in to segmental arteries supplying the renal vascular segments. Accessory renal arteries are common and arise from the aorta above or below the main renal artery, rarely arise from superior mesenteric artery or near the aortic bifurcation or from the common iliac arteries. ${ }^{[1]}$ These are regarded as persistent embryonic lateral splanchnic arteries. In $35 \%$ of individuals accessory renal artery is present. Pick and Anson found accessory renal arteries in $32.25 \%$ cases. $^{[2]}$ Mishra et $\operatorname{al}(2013),{ }^{[3]}$ also observed that $32 \%$ cases showed presence of accessory arteries. Saldarriaga et al, ${ }^{[4]}$ found them in $22.5 \%$ cases.

\section{Subjects and Methods}

Sixty patients who came for abdominal CT were included in the study. The age was in between 25 to 62 years. Out of 60 patients 23 were male and 37 were female patients. The patients had undergone angiography for the following reasons-abdominal pain, liver tumor, liver metastasis; aneurysm of abdominal aorta, willing for donor nepherectomy etc .Exclusion criteria was pregnant women, patient with impaired renal function. Detailed angiographic procedure and probable complications are explained and the informed consent was received from all without additional intervention on the patients. 64 slice VCT Xt high speed advantage scanner, helical computed tomography, consist of slice thickness $(5 \mathrm{~mm})$ with contrast $80 \mathrm{ml}$ of iodine (inj omnipaque) $140 \mathrm{mg} \backslash \mathrm{ml}$ at the rate of $4.5 \mathrm{ml} \backslash \mathrm{sec}$. with power injector. Helical CT scan is performed for arterial phase after 18-22 sec at. $5 \mathrm{~mm}$ slice and venous phase after $45-50 \mathrm{sec}$.

\section{Results \& Discussion}

This study has shown that all the renal arteries arises from the abdominal aorta. The presence of accessory renal artery was observed in 21 cases out of 60 i.e $35 \%$ and more common on left side i.e $47 \%$ (10 out of 21 cases) than $38 \%$ (8 out of 21 cases) on right side .Bilateral accessory artery found in 3out of 21 cases i.e 14\%.This study shown that 


\section{Anurang d Gupta, Variatians of Renal Artery - A Multi-Detectar Camputed Jamagraphy Study}

mean length of right renal artery was more than left renal artery .No significant difference regarding length according to side were found in accessory renal artery while the accessory renal artery had greater length than the main arteries .The diameter of accessory renal artery was found less than main artery. Mode of termination of renal artery was hilar in 31 cases i.e $55 \%$ and renal artery divides earlier than the hilum in 29 cases i.e $45 \%$.

Table 1: Incidence and side of accessory renal artery

\begin{tabular}{|l|c|c|}
\hline Renal artery & No. Of cases & Percentage \\
\hline Single renal artery & 39160 & $65 \%$ \\
\hline Accessory renal artery & 21160 & $35 \%$ \\
\hline $\begin{array}{l}\text { Rt accessory renal } \\
\text { artery }\end{array}$ & 8121 & $38 \%$ \\
\hline $\begin{array}{l}\text { Lt accessory renal } \\
\text { artery }\end{array}$ & 10121 & $47 \%$ \\
\hline $\begin{array}{l}\text { Bilateral accessory } \\
\text { renal artery }\end{array}$ & 3121 & $14 \%$ \\
\hline
\end{tabular}

Table 2: Mean length and mean diameter of normal and accessory renal artery

\begin{tabular}{|l|c|c|}
\hline Renal artery & Mean length & Mean diameter \\
\hline Right renal artery & $34.2 \mathrm{~mm} \_+4.05 \mathrm{~mm}$ & $4.6 \mathrm{~mm}+\_.52 \mathrm{~mm}$ \\
\hline Left renal artery & $27.6 \mathrm{~mm} \_+5.00 \mathrm{~mm}$ & $4.8 \mathrm{~mm}+\_.54 \mathrm{~mm}$ \\
\hline $\begin{array}{l}\text { Rt accessory renal } \\
\text { artery }\end{array}$ & $47.1 \mathrm{~mm}+4.29 \mathrm{~mm}$ & $1.9 \mathrm{~mm}+0.50 \mathrm{~mm}$ \\
\hline $\begin{array}{l}\text { Lt accessory renal } \\
\text { artery }\end{array}$ & $40.0 \mathrm{~mm} \_+5.27 \mathrm{~mm}$ & $2.3 \mathrm{~mm}+\_0.53 \mathrm{~mm}$ \\
\hline
\end{tabular}

Table 3: Incidence of number of accessory renal artery

\begin{tabular}{|c|c|c|c|}
\hline $\begin{array}{l}\text { No of accessory } \\
\text { renal artery }\end{array}$ & Right & Left & Bilateral \\
\hline One & 7 & 9 & 3 \\
\hline Two & 1 & 1 & 0 \\
\hline
\end{tabular}

Anshu Mishra et al (2013), ${ }^{[3]}$ studied the variation in number and vertebral level of origin of renal artery in North Indian population. They observed $32 \%$ cases showed presence of accessory renal artery, and incidence of accessory renal artery was slightly higher on left side i.e. $18.86 \%$ than on the right side i.e. $16.98 \%$. The incidence of accessory renal artery was found to be higher is females as compared to males. It is similar to present study where we found accessory renal artery in 21 cases out of 60 cases i.e 35\%, bilateral accessory renal artery in 3 cases and two accessory renal artery seen in 2 cases K.Munnusamy etal (2016), ${ }^{[5]}$ observed in their angiographic study of 100 patients that $38 \%$ cases had accessory renal artery. Incidence of accessory renal artery was equally distributed on both side respectively (13\% on right and left) $12 \%$ shows accessory renal artery on both side. C Cinar et al (2016), ${ }^{[6]}$ study 504 MDCT patients accessory renal artery was $31.3 \%$ (22.2\% for two renal artery, $7.5 \%$ for three renal artery, $1.4 \%$ for four renal artery, $0.2 \%$ for five renal artery, prehilar branching was $6.5 \%$ ).

MV Ramulu et al(2016), ${ }^{[7]}$ studied 50 specimens from 25 adult cadaver they found accessory renal artery in $24 \%$ of cases with equal incidence on both side. Within accessory hilar type was most common (14\%) followed by inferior polar in $12 \%$, superior polar in $2 \%$. A.A Jamkar et al (2017), ${ }^{[8]}$ was observed accessory renal artery in $24.99 \%$ kidney, one accessory renal artery in $20.75 \%$,two accessory renal artery in $4.24 \%$ kidney.

B. Saldarriaga et al $(2008),{ }^{[4]}$ studied the frequency of additional renal arteries and their morphological expression in colombian population. They observed an additional renal artery in $22.5 \%$ of population, most frequently found on left side, arise from the aorta's lateral aspect and usually entered the renal parenchyme through the hilum. They also found two additional renal arteries in $2.6 \%$ of same sample, .These studies were different from our study.

Hemanth Komvuru et al (2012), ${ }^{[9]}$ observed that out of 184 kidney 52 kidneys showed the presence of accessory renal arteries. Out of 52 kidneys 34 kidneys had one additional artery and 18 kidneys had two additional arteries. Out of 52 kidneys in 23 kidneys had additional artery was observed towards the superior pole (superior polar artery) was observed and 29 kidneys inferior polar artery was seen. The presence of additional renal arteries were found unilaterally in 6 cadavers and bilaterally in 20 cadavers.

Krunal Chauhan et al (2013), ${ }^{[10]}$ studied forty cadavers, out of which they found anomalies of renal arteries in 20 cadavers $(50 \%)$. In which bilateral variation were found in 6 cadavers and unilateral variation were found in 14 cadavers. Out of 80 kidney specimens in $10(12.5 \%)$ kidneys they observed superior polar artery, in $10(12.5 \%)$ inferior polar artery and in 20 (25\%) kidney specimen superior and inferior polar arteries both were present. In most of the cases they were arising from the abdominal aorta except in one case inferior renal polar artery was arising from the renal artery. S Manupati et al (2014), ${ }^{[11]}$ study 24 cadaver found one accessory renal artery in 3cadaver (12.5\%), bilateral accessory renal artery in 2 cadever $(8.4 \%)$,In one case triple renal artery on right side and double renal arteries on left side. Right renal artery is longer than left renal artery i.e $46.4 \mathrm{~m} . \mathrm{m}$ on right side and $36.6 \mathrm{~m} . \mathrm{m}$ on left side similar results shown by Pushp Dhar and K.Lal 2005. ${ }^{[12]}$ Our study shown predominance of accessory renal artery on left side as compared to right side similar to finding of Saldarriage. B $2008,{ }^{[4]}$ and Ragiba Zagypan etal 2009. ${ }^{13]}$ And this is also supported by the work of Satypal et al (2011). ${ }^{[14]}$ The accessory renal artery is more on left side (27.6\%) than on right side $(18.6 \%)$ and William 2005, ${ }^{[15]} 30 \%$ and Tropmann 2001 and $33.3 \%$ cases found in study of zelalem Animaw et al (2018). ${ }^{[16,17]}$

\section{Embryological Basis-}

Presence of accessory renal artery can be explained in the light of embryogenic development and its molecular regulation.

Each primitive dorsal aorta gives off ventral splanchnic arteries lateral splanchinc artery, somatic arteries and caudal continuation. The lateral splanchinc arteries supply on each side the mesonephros, metanephros, the testis or ovary and suprarenal gland. All these structures develop, in whole or in part from the intermediate mesenchyme of the mesonephric ridge. One testicular or ovarian artery and three suprarenal arteries persist on each side. The phrenic artery branches from the most cranial suprarenal artery and the renal artery arises from the most caudal one. Accessory renal arteries are frequentely present and may be looked on as branches of persistent lateral splanchnic arteries. ${ }^{[18]}$ Misexpression of one or more transcription factors i.e vascular endothelial growth factor VEGF, ephrin B2 may lead to aberration in the arterial development. ${ }^{[19]}$ During the changes in kidney 


\section{Anurag \& Gupta; Variations of Renal Artery - A Multi-Detectar Camputed Jamagraphy Study}

position, they receive their blood supply from vessels that are close to them .Initially the renal arteries are branches of the common iliac arteries .Later the kidneys receive their blood supply from the distal end of aorta. When they are located at the higher level, they receive new branches from the aorta .Normally the caudal branches of the renal vessels undergo involution and disappears. ${ }^{[20]}$

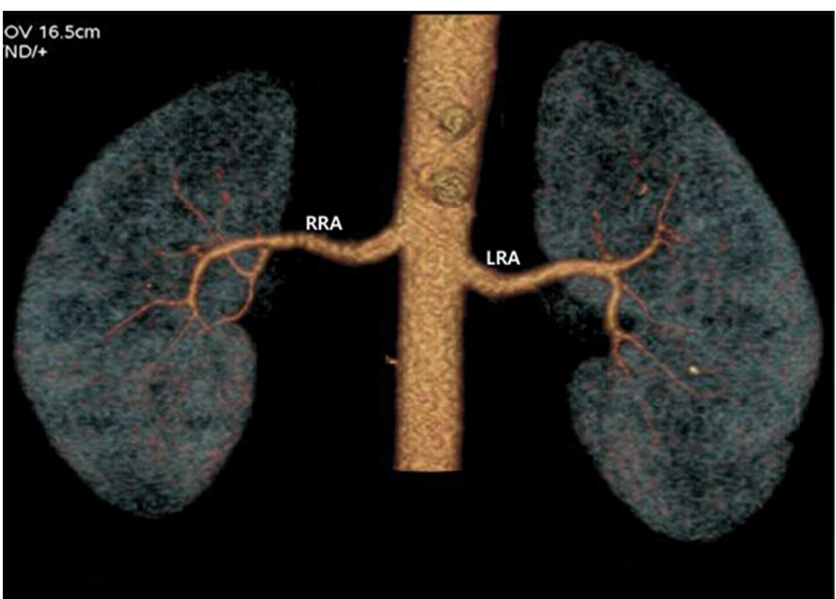

Figure 1: Single renal artery (RRA- Right Renal Artery, LRALeft Renal Artery)

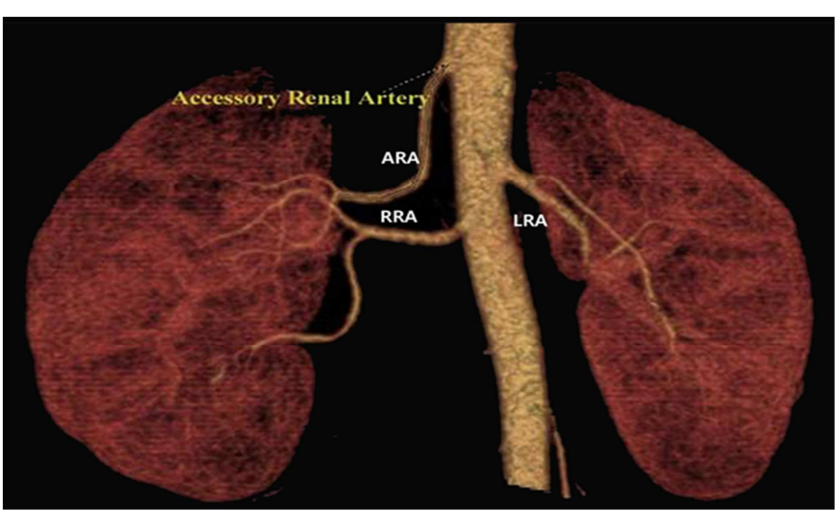

Figure 2: Right Accessory Renal Artery (RRA- Right Renal Artery, LRA- Left Renal Artery, ARA- Accessory Renal Artery)

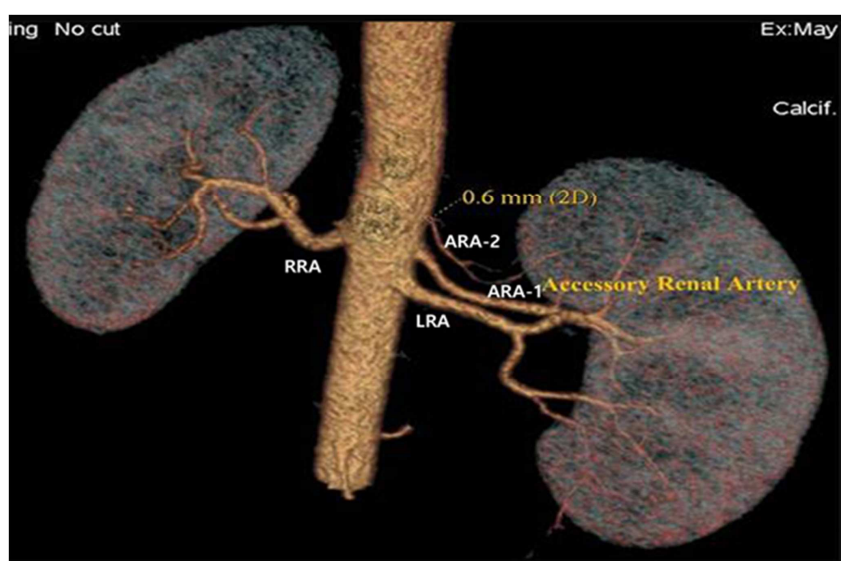

Figure 3: Double Accessory Renal Artery on Left Side (RRARight Renal Artery, LRA- Left Renal Artery, ARA- Accessory Renal Artery)

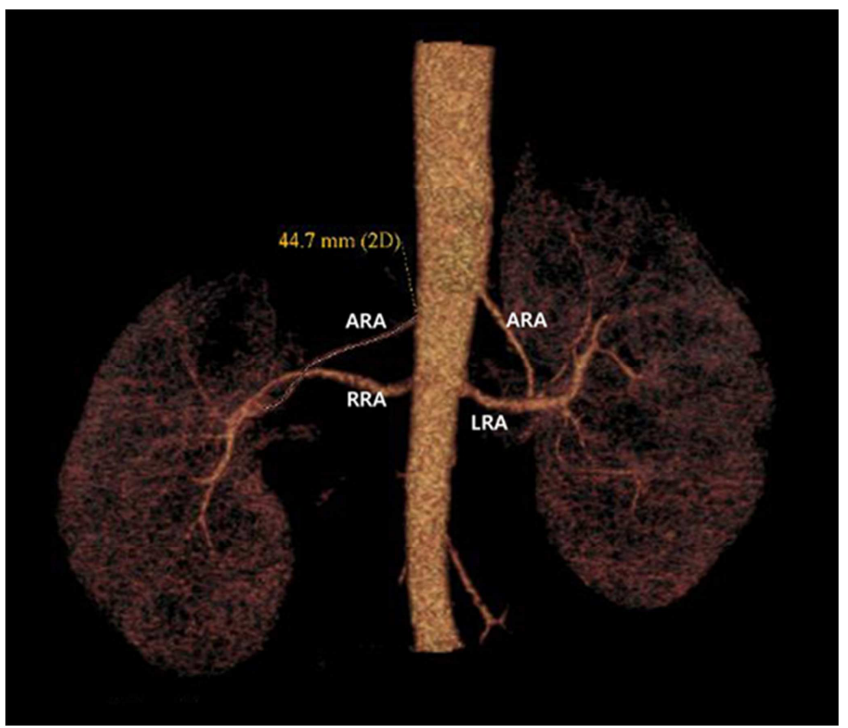

Figure 4: Bilateral Accessory Renal Artery (RRA- Right Renal Artery, LRA- Left Renal Artery, ARA- Accessory Renal Artery)

\section{Conclusion}

Considering the increase in incidence of the accessory renal artery the anatomical knowledge of such may be important for academic, surgical as well as radiological procedures. In order to know the vascular pattern and to plan appropriate surgical procedure CT angiography should be performed prior to every nepherectomy. Polar arteries are segmental arteries and if damaged produce infarction of that segment of the kidney. Presence of multiple renal arteries poses difficulties during surgical procedures .Inferior polar artery cross anterior to ureter and may be obstructing the ureter, cause hydronephrosis.

\section{References}

1. Standring S. Gray's Anatomy. The anatomical basis of clinical practice, kidney and ureter; 40th ed. Churchill \& Livingstone Elsevier, London 2008; p. 1231-1232.

2. Pick JW and Anson BJ. The renal vascular pedicle : An anatomical study of 430 body halves. J. Urol. 1940; 44:411.

3. Mishra A, Sharma PK, Manik P, Singh R, Singh SK. Variation in number and vertebral level of origin of renal artery in North India population; Journal of biological and chemical research; 2014; 31(1): 182-191.

4. Saldarriage B, Perez AF, Ballesteros LE. A direct anatomical study of additional renal arteries in a colombian mestizo poplation, Folia Morphol, 2008; 67: 129-134.

5. Munnusamy K, Kasirajan SP,etal.Varitions in branching pattern of renal artery in kidney donors using angiography, JCDR 2016 ;10(3):1-3

6. Cinar C.,Turkvatan A. Prevalance of renal vascular variations:evaluation with MDCT angiography ;Diagnostic and interventional imaging 2016;97:891-897.

7. Ramulu MV and Prasanna LC .Accessory renal arteries anatomical details with surgical perceptions;JASI 2016;65:S55S57.

8. Jamkar AA,Khan B,etal.Anatomical study of renal and accessory renal arteries;Saudi journal of kidney diseases \&transplantation;2017;28(2)292-297.

9. Kommuru H, Sreelekha D, Jothi SS, Rajeswaraer N, Swatha N. Presence of renal artery variations and its surgical correlation; 


\section{Anurag d Gupta, Variations of Renal Artery - A Multi-Detectar Camputed Jamagraphy Study}

International Journal of Medical and Clinical research 2012; 3; 176-179.

10. Chauhan K, Patel SJ Patel RK, A Mehta CD, Desai M. Variant origin of renal arteries and its clinical implication; CIB Tech Journal of Surgery 2013; 2(2) : 7-12.

11. Manupati S,Velichety SD,etal.Bilateral renal artery variations embryological significance and clinical implications;IJCRR 2014;6(2):

12. Dhar P, Lal K. Main and accessory renal arteries - A morphological study. IT. J. Anat embryo, 110(2): 101-10, (2005).

13. Zagyapan R, Pelin C, Kurkcuoglu A. A retrospective study on multiple renal arteries in Turkish population; anatomy international journal of experimental and clinical anatomy 2009; 35-39.

14. Satyapal KS, Haffejee AA, Singh B, Ramsaroop L, Robbs JV, Kalideen JM. "Additional renal arteries : incidence and morphometry", Sur. Radiol. Anat. 2001; 23(1) 33-38.

15. Williams in : Gray's anatomy - The anatomical basis of clinical practice, 39th edition, churchill livingstone, 2005; 1044-1274.

16. Troppmann G. Increased transplantation of kidneys with multiple renal arteries in the laproscopic live donor nephrectomy era, surgical technique, surgical and non surgical donor and recipient outcomes, Arch.Surge, 2001; 136(8): 897-907.

17. Animaw Z,Worku A,Muche A.Renal artery origins,destination and variations cadaveric study in ethopian population.IT.J.Anat.Variation.11(1)2018.

18. Standing S, Ellis H, Healy JC, Johnson D, Williams A. et al. Gray's Anatomy. 39th Edition Philadelphia Elsevier Churchill Livingstone. 2005; 1274:1042.

19. Sadler TW. Langman's Medical Embryology. In : Third to eighth weeks : The embryonic period. 11th ed. Lippincott Williams \& Wilkins. Philadelphia, USA. 2010; 81-82.

20. Moore K, Persaud TVN. The developing human - clinically oriented embryology. The urogenital system. 8th edn. Saunders Elsevier, 2008. 249-50.

Copyright: ( $)$ the author(s), publisher. Academia Anatomica International is an Official Publication of "Society for Health Care \& Research Development". It is an open-access article distributed under the terms of the Creative Commons Attribution Non-Commercial License, which permits unrestricted non-commercial use, distribution, and reproduction in any medium, provided the original work is properly cited.

How to cite this article: Anurag, Gupta V. Variations of Renal Artery - A Multi-Detector Computed Tomography Study. Acad. Anat. Int. 2019;5(2):69-72.

DOI: dx.doi.org/10.21276/aanat.2019.5.2.19

Source of Support: Nil, Conflict of Interest: None declared. 